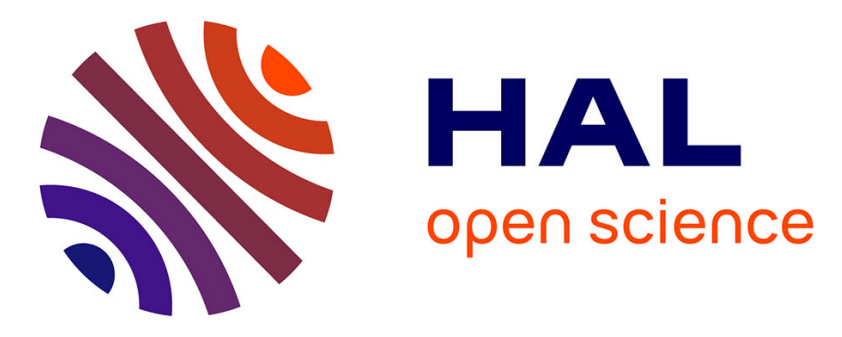

\title{
Measure of fracture toughness of compressive fiber failure in composite structures using infrared thermography
}

Teddy Lisle, Christophe Bouvet, Natthawat Hongkarnjanakul, Marie-Laetitia Pastor, Samuel Rivallant, Philippe Marguerès

\section{To cite this version:}

Teddy Lisle, Christophe Bouvet, Natthawat Hongkarnjanakul, Marie-Laetitia Pastor, Samuel Rivallant, et al.. Measure of fracture toughness of compressive fiber failure in composite structures using infrared thermography. Composites Science and Technology, 2015, 112, pp.22-33. 10.1016/j.compscitech.2015.03.005 . hal-01847367

\section{HAL Id: hal-01847367 https://hal.science/hal-01847367}

Submitted on 23 Jul 2018

HAL is a multi-disciplinary open access archive for the deposit and dissemination of scientific research documents, whether they are published or not. The documents may come from teaching and research institutions in France or abroad, or from public or private research centers.
L'archive ouverte pluridisciplinaire HAL, est destinée au dépôt et à la diffusion de documents scientifiques de niveau recherche, publiés ou non, émanant des établissements d'enseignement et de recherche français ou étrangers, des laboratoires publics ou privés. 


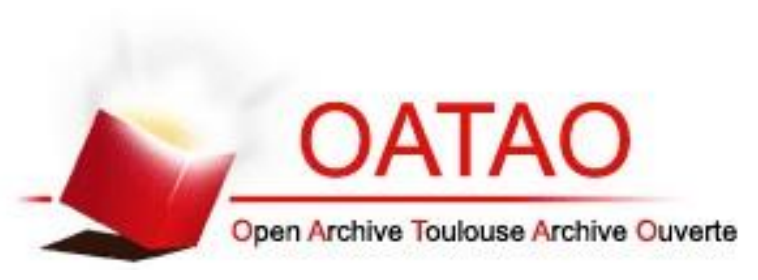

\section{Open Archive Toulouse Archive Ouverte (OATAO)}

OATAO is an open access repository that collects the work of Toulouse researchers and makes it freely available over the web where possible.

This is an author -deposited version published in: http://oatao.univ-toulouse.fr/ Eprints ID: 5112

To link to this article: doi:10.1016/j.compscitech.2015.03.005

URL: http://dx.doi.org/10.1016/j.compscitech.2015.03.005

To cite this version: Lisle, Teddy and Bouvet, Christophe and Hongkarnjanakul, Natthawat and Pastor, Marie-Laetitia and Rivallant, Samuel and Margueres, Philippe Measure of fracture toughness of compressive fiber failure in composite structures using infrared thermography. (2015) Composites Science and Technology, vol. 112. pp. 22-33. ISSN 0266-3538

Any correspondence concerning this service should be sent to the repository administrator: staff-oatao@inp-toulouse.fr 


\title{
Measure of fracture toughness of compressive fiber failure in composite structures using infrared thermography
}

\author{
Teddy Lisle, Christophe Bouvet*, Natthawat Hongkarnjanakul, Marie-Laetitia Pastor, Samuel Rivallant, \\ Philippe Margueres
}

Université de Toulouse; ICA (Institut Clément Ader)

ISAE (Institut Supérieur de l'Aéronautique et de l'Espace), 10, avenue Edouard Belin, BP 54032, 31055 Toulouse cedex 4, France

Keywords:

B. Fracture toughness

D. Thermography

D. Infrared camera

C. Non-destructive testing

\begin{abstract}
A B S T R A C T
Fracture toughness is one of the most important properties of any material for a lot of design applications involving damage and crack growth. Unfortunately, its value can be difficult to evaluate with standard methods such as the "compliance" method. In this work, two special cases have been studied and infrared thermography has been used to overcome the limitations of conventional methods.

Compressive fiber failure in unidirectional composite laminate has been chosen due to its difficulty to evaluate toughness. Infrared thermography has been employed to follow compressive failure mode developing during an indentation test and a compression after impact test, and to evaluate the fracture toughness of compressive fiber failure. The obtained results show a good correspondence with the value found in a previous work on FE analysis of impact damage and are consistent with the literature.
\end{abstract}

\section{. Introduction}

The design optimization process of composite structures is classically accelerated by using numerical approach. Finite element analysis (FEA) is extensively elaborated thanks to its ability to precisely simulate particular damage of laminated composites i.e. fiber failure, matrix cracking and delamination. To date, material law regarding fracture mechanics seems to be a reasonable damage model in FEA since it can provide accurate damage results [1-5]. With this approach, fracture energies are required as input parameters for the model. However, these properties can be difficult to determine. Besides, standardized tests have not been established yet [1,6-9]. For standard damage phenomena, such as delamination between plies of a composite laminate plate, the experimental tests are well defined: the DCB (Double Cantilever Beam) test is currently carried out to evaluate fracture toughness in opening failure mode and ENF (End Notched Flexure) is often used to evaluate fracture toughness in shear mode [8-10]. The problem is more difficult for complex damage phenomena, such as compressive fiber failure, for which the crack induces a lot of secondary damage types. Indeed the failure mode of compressive fiber failure in laminated composites $[6,7,11,12]$ is known as a very complex mode, occurring as a result of local buckling of fibers and leading to the kinking process (Fig. 1).

\footnotetext{
* Corresponding author.

E-mail address: christophe.bouvet@isae.fr (C. Bouvet).
}

Currently, no standard tests are available to determine the fracture toughness of this phenomenon and the compact compression (CC) test is currently used. Fig. 1c shows a micrographic observation done by Gutkin et al. [12] showing clearly the phenomenon of kink band at the crack tip followed by a phenomenon of crushing. Then to evaluate the fracture toughness of this crack, it is necessary to separate these two phenomena - kink band and crushing. For this purpose, a local approach is needed. This observation is confirmed by Pinho et al. [6] who showed that the zone concerned by the damage in compression is very large, unlike in the case of tension (Fig. 2). The authors conclude "for kink-band formation, propagation values cannot be obtained directly from a stress intensity factor approach because the contact stresses in the faces of the kink cannot be easily accounted for; the area method also failed to produce meaningful results due to kink band broadening and delamination" [6]. Then, local approach is needed to evaluate dissipated energy by compressive fiber failure and the infrared thermography technique may be an answer to this problem.

In this paper, infrared thermography has been used to follow compressive failure mode developed during an indentation test and a compression after impact test, and to evaluate the fracture toughness of compressive fiber failure. From the past 20 years, infrared thermography has been widely used to study the dissipative phenomena in materials, such as plasticity in metals $[13,14]$ or damage in polymers [15]. Using the framework of irreversible thermodynamics, Chrysochoos et al. [16] have presented a methodology to estimate the internal heat sources associated with the 


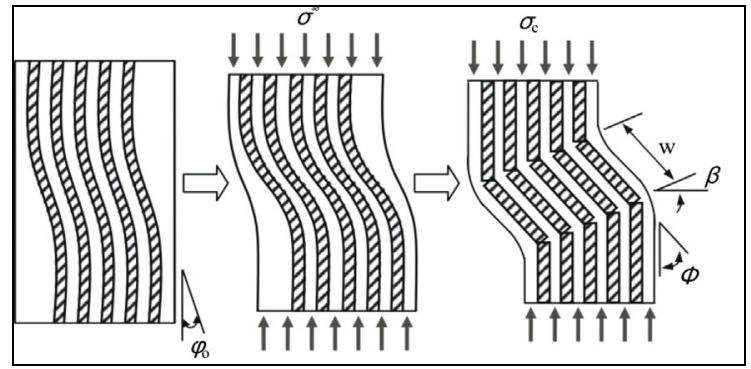

(a)

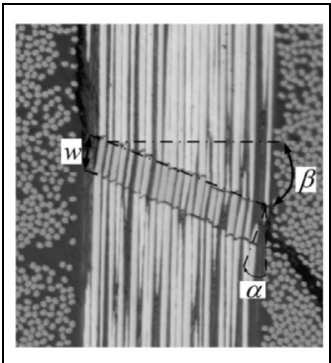

(b)

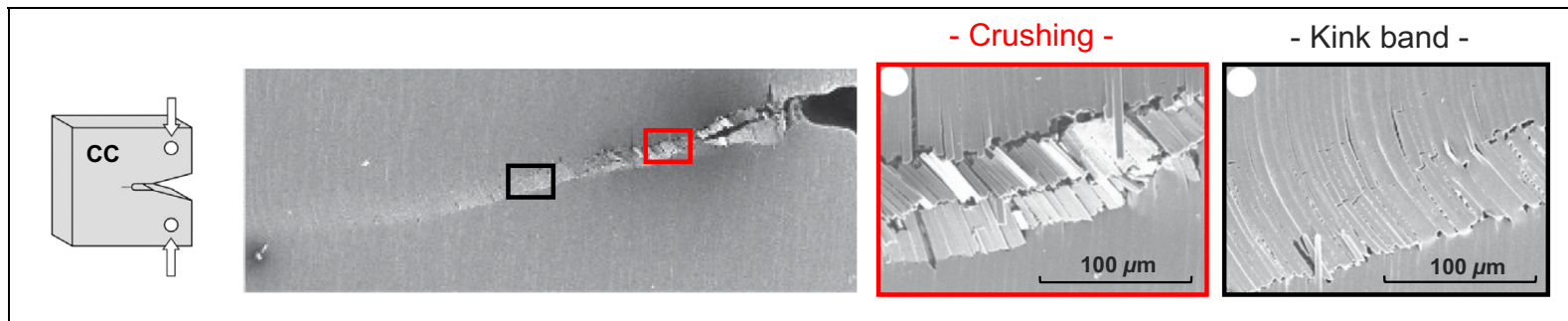

(c)

Fig. 1. Compressive fiber failure by kinking process: principle [11] (a), micrographic observation [12] (b) and micrographic observation during a CC test [12] (c).

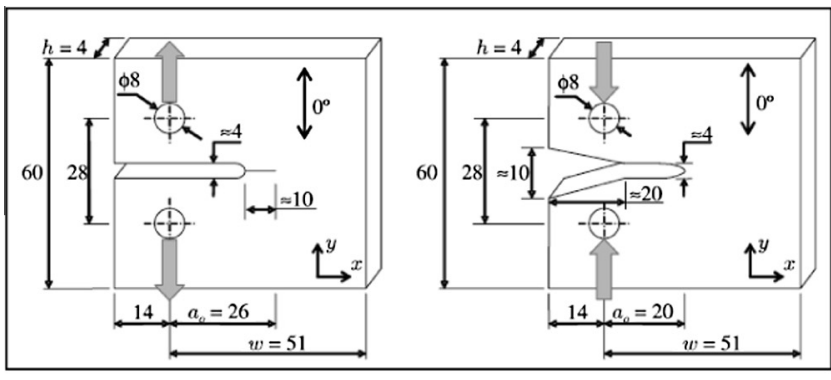

(a)

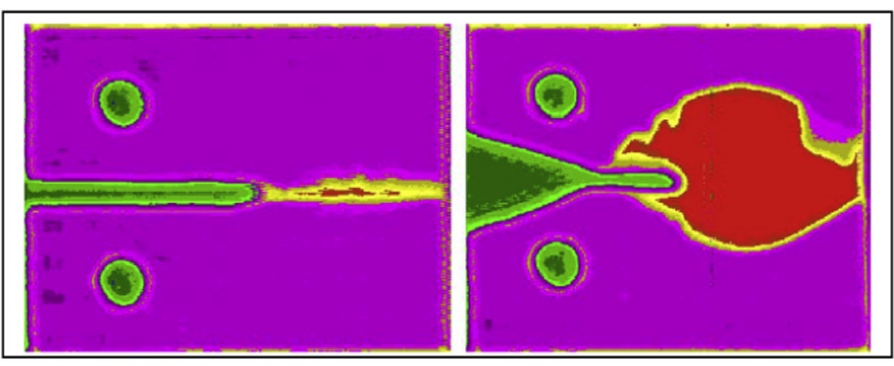

(b)

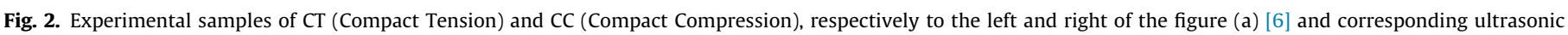
observations (b) [6].

dissipative phenomenon from temperature measurement on the sample surface. They show that an estimation of the heat sources makes it possible to locate the damage in time and space and to evaluate the dissipated thermal energy. Nevertheless, the study of dissipated thermal energy by infrared thermography is quite recent in composite materials and is essentially applied to fatigue loading. For example, Naderi et al. [17] used infrared thermography to characterize damage stage evolution by calculating the dissipated heat during fatigue loading of thin woven laminates. They show it is possible to characterize the three characteristic stages of fatigue damage of a woven glass/epoxy using IRT and they compare this technique with acoustic emission. The results of the two non-intrusive techniques show similar response revealing the existence of three degradation stages [17]. Nevertheless, applying crack tip contour integral analysis [18], Freund and Hutchinson [19] and Soumahoro [20] have shown that the fracture toughness is linked to dissipative work. In addition, since the early work of Taylor and Quinney [21], it is well known that dissipative work is mainly converted into heat in metallic [22] and polymeric materials [23]. For example, Kapoor and Nemat-Nasser [22] show the infrared measurement yields more than $70 \%$ conversion of work to heat for Taork is mainly converted into heat in metallic [since the early work of Ta. Then for this case, the ratio of dissipative work converted into heat should be close to $100 \%$. For polymeric materials, the problem is more complex. $\mathrm{Li}$ and Lambros [23] studied a polymethyl methacrylate (PMMA) and a polycarbonate (PC) at different strain rates $\left(10^{-4}-10^{3} \mathrm{~s}^{-1}\right)$. For PC the ratio of dissipative work converted into heat is between $100 \%$ for low strain and 50\% for high strain and for PMMA, the brittle nature of the material does not permit to define the ratio.

Hence, in this study we propose to link the fracture toughness to the experimental heat sources [24]. In this way, the fracture toughness can be computed even for experiments where the stiffness variation remains small and for which the standard techniques, such as area or compliance methods, are not relevant. Indeed the main drawback of the standard techniques is to sum the dissipated energy of all the damage types of the sample and as a result to overestimate the value of the fracture toughness. For example for an ENF test, the area method adds the dissipated energy due to propagation of the crack in mode II but also the dissipated energy due to the crushing of the beam under the boundary conditions.

The fiber compressive failure is usually considered as a complex failure mode $[6,7,11,12]$. Furthermore, the critical energy release rate in compression, $G_{I c}^{\text {comp }}$ (generally referred to mode I intralaminar fracture) is even more complex. Different approaches have been proposed in the literature to determine this value. For 
example, Pinho et al. [6] used compact compression (CC) tests to evaluate the fiber $G_{\text {Ic }}^{\text {comp }}$ of T300/913 carbon-epoxy laminates. Initiation toughness value for kink-band formation was obtained equal to $79.9 \mathrm{~N} / \mathrm{mm}$, whereas the propagation was not reliable due to an appearance of other failure modes such as crushing or delamination. Soutis and Curtis [7] also measured the $G_{\text {Ic }}^{\text {comp }}$ of T800/924C carbon-epoxy $\left[0,90_{2}, 0\right]_{3 s}$ UD laminates. The values calculated by analytical formulations based on elastic laminated properties were determined to be equal to $\approx 34-39 \mathrm{~N} / \mathrm{mm}$. The two studies show clearly the difficulty to evaluate the compressive fiber fracture toughness. These two values of $G_{I c}^{\text {comp }}$ can be compared to the one from Hongkarnjanakul et al. [25]. In this study, the authors have found that the value of $G_{I c}^{c o m p}$ for a T700GC/M21 UD-ply that best fitted the results of their FE model compared to experiments in terms of impact damage - compressive crack size on impacted surface and delamination shape - was $40 \mathrm{~N} / \mathrm{mm}$. Indeed, the estimation of $G_{I c}^{\text {comp }}$ was performed because this value was not available in the literature. The authors concluded that a complementary test should be reflected to determine compressive fiber toughness [25]. In another way, an infrared thermography technique is being developed in our laboratory ICA by Lisle et al. [24] to define this value. This technique was successfully used to measure intralaminar transverse weft cracking of thin woven laminates. As a result of this work, it is a challenge to use this methodology to UD laminates. Thus, the present work is aimed to use the methodology related to infrared thermography developed in [24] to measure $G_{I c}^{\text {comp }}$ from applications and material of [25].

\section{Experimental tests}

Indeed, the first step to evaluate $G_{I c}^{\text {comp }}$ is to choose the appropriate test. The test should promote compressive fiber failure as pure and stable as possible. In fact it is almost impossible to exhibit only compressive fiber failure because it is a very complex failure mode which is followed by secondary failure modes such as delamination or matrix cracking $[6,7,11,12]$. Moreover the stacking sequence has much effect on the failure mode. In fact it could be interesting to use pure unidirectional laminate to isolate the compressive fiber failure mode, but it is uncertain the failure mode is similar to the one developing in a multidirectional laminated composite. Then in this study two applications with a multidirectional laminated composite have been chosen to be representative of a real composite structure. The first application deals with an impact test and the second application deals with a compression after impact test.

Both tests are operated at room temperature $(\approx 293 \mathrm{~K})$. An infrared camera (FLIR SC700 MW) is used to monitor the thermal response during the tests. The infrared camera has a maximum resolution of $320 \times 256$ pixels and a thermal resolution of $0.025 \mathrm{~K}$ for relative temperature measurement. The spatial resolution (pixel size) determined by the focal distance is set at $0.16 \mathrm{~mm}$ (maximum magnification of the lens). In order to avoid thermal perturbation from the external environment, the specimens are enclosed both in a black painted box covered with a black opaque fabric outside. Thermal images were recorded at a frequency of $50 \mathrm{~Hz}$. This frequency is high enough to obtain a good description of the studied phenomenon and to avoid an excessively large recorded file. Indeed even if the studied phenomenon is very fast, such as unstable crack growth, the temperature conduction is a relatively low phenomenon, of course depending on the material conductivity. In this case, the conduction phenomenon typically lasts one second (Fig. 9a and 10a) and a frequency of $50 \mathrm{~Hz}$ is quite sufficient to observe it.

The first application deals with a compressive fiber crack on the surface of a $\left[90_{2}, 0_{2},-45_{2}, 45_{2}\right]_{s}$ laminate during an impact test [25] (Fig. 3a). Due to the shorter edge boundary conditions in the $90^{\circ}$ direction, during the global bending of the plate, the outermost $90^{\circ}$-plies are subjected to higher compressive stresses than the inner plies. As a result, compressive fiber failure cracks are generated in the upper layers. In fact, a static indentation test was carried out instead of impact test; because we need a long test to observe damage by using infrared thermography camera. The second test application is compression after impact (CAI) (Fig. 3b).

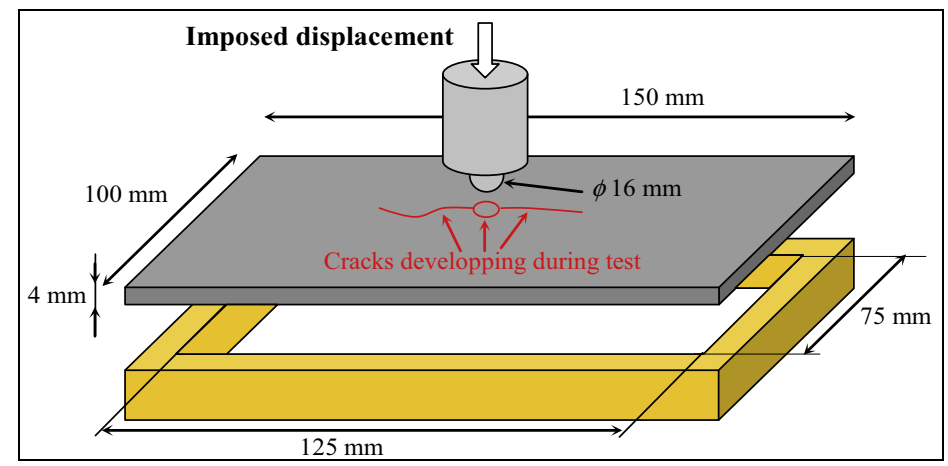

(a)

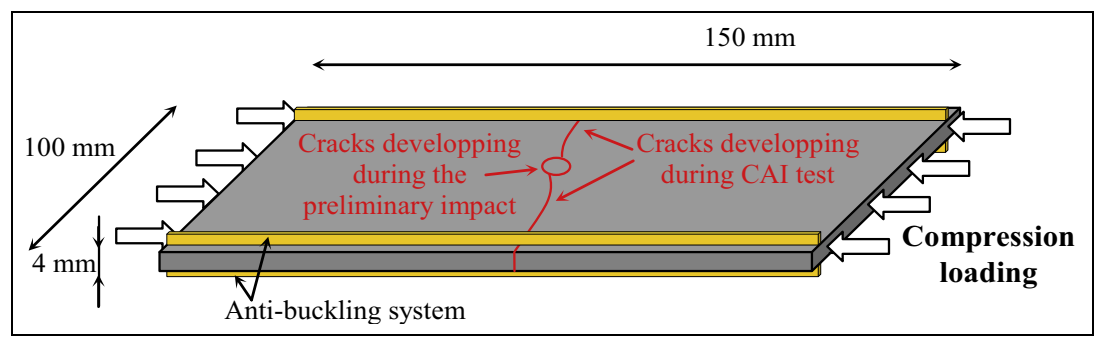

(b)

Fig. 3. Experimental setup of impact/indentation test (a) and compression after impact test (b). 
Table 1

Mechanical and thermal properties of T700GC/M21 (carbon/epoxy) UD ply [10,2729].

\begin{tabular}{ll} 
Compressive Young's modulus in fiber direction, $E_{l}^{c}$ & $100 \mathrm{GPa}$ \\
Transverse Young's modulus, $E_{t}$ & $7.7 \mathrm{GPa}$ \\
Shear modulus, $G_{l t}$ & $4.8 \mathrm{GPa}$ \\
Poisson's ratio, $v_{l t}$ & 0.33 \\
Thermal conductivity in fiber direction, $k_{l l}[27]$ & $6.3 \mathrm{~W} \mathrm{~m}^{-1} \mathrm{~K}^{-1}$ \\
Thermal conductivity in transverse direction, $k_{t t}$ and $k_{z z}[28]$ & $0.5 \mathrm{~W} \mathrm{~m}^{-1} \mathrm{~K}^{-1}$ \\
Specific heat, $C[29]$ & $902 \mathrm{~J} \mathrm{~kg}^{-1} \mathrm{~K}^{-1}$ \\
Density, $\rho$ & $1600 \mathrm{~kg} \mathrm{~m}^{-3}$ \\
\hline
\end{tabular}

Failure of the outermost $0^{\circ}$-plies of a $\left[0_{2}, 45_{2}, 90_{2},-45_{2}\right]_{s}$ laminate, directly subjected to compressive loading, is investigated. Then, the critical energy release rate is measured based on an evaluation of the heat dissipation on the observed compressive cracks. The material used in this study is a T700GC/M21 carbon/epoxy UD prepreg with $0.25 \mathrm{~mm}$-ply thickness (Table 1 ). The laminates are 16plies, balanced, symmetrical and quasi-isotropic with a total thickness of about $4 \mathrm{~mm}$. They are cut into $100 \times 150 \mathrm{~mm}^{2}$ rectangular plates according to the Airbus Industries Test Method (AITM 10010) for impact and CAI (Compression After Impact) tests.

The static indentation test (Fig. 3a) is similar to an impact test: a $100 \times 150 \mathrm{~mm}^{2}$ rectangular plate specimen is simply supported on a $75 \times 125 \mathrm{~mm}^{2}$ frame. The loading is applied through a $16 \mathrm{~mm}-$ diameter spherical indenter at the center of the specimen with a $5 \mathrm{~mm} / \mathrm{min}$ displacement rate. A LVDT sensor is used to measure the displacement of the crosshead. During the test, compressive

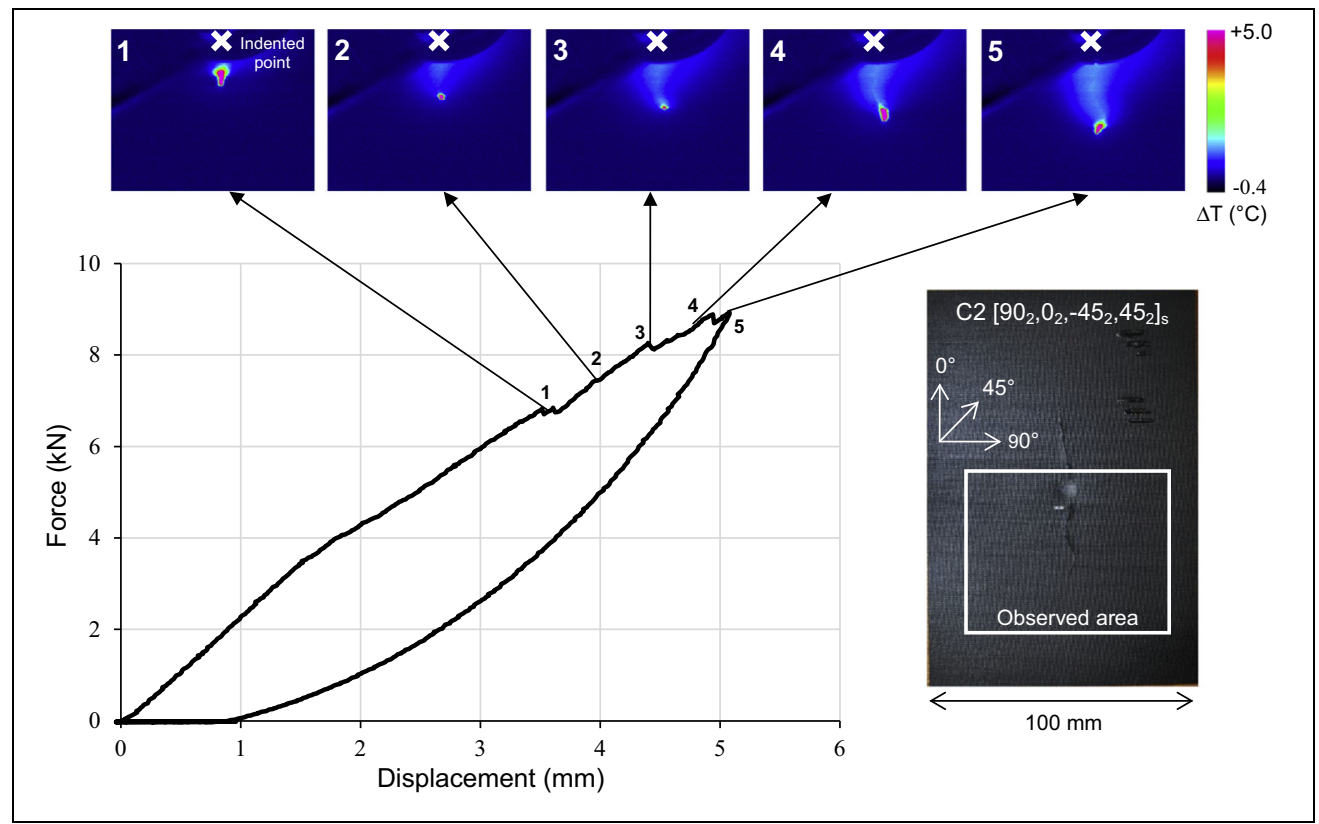

(a)

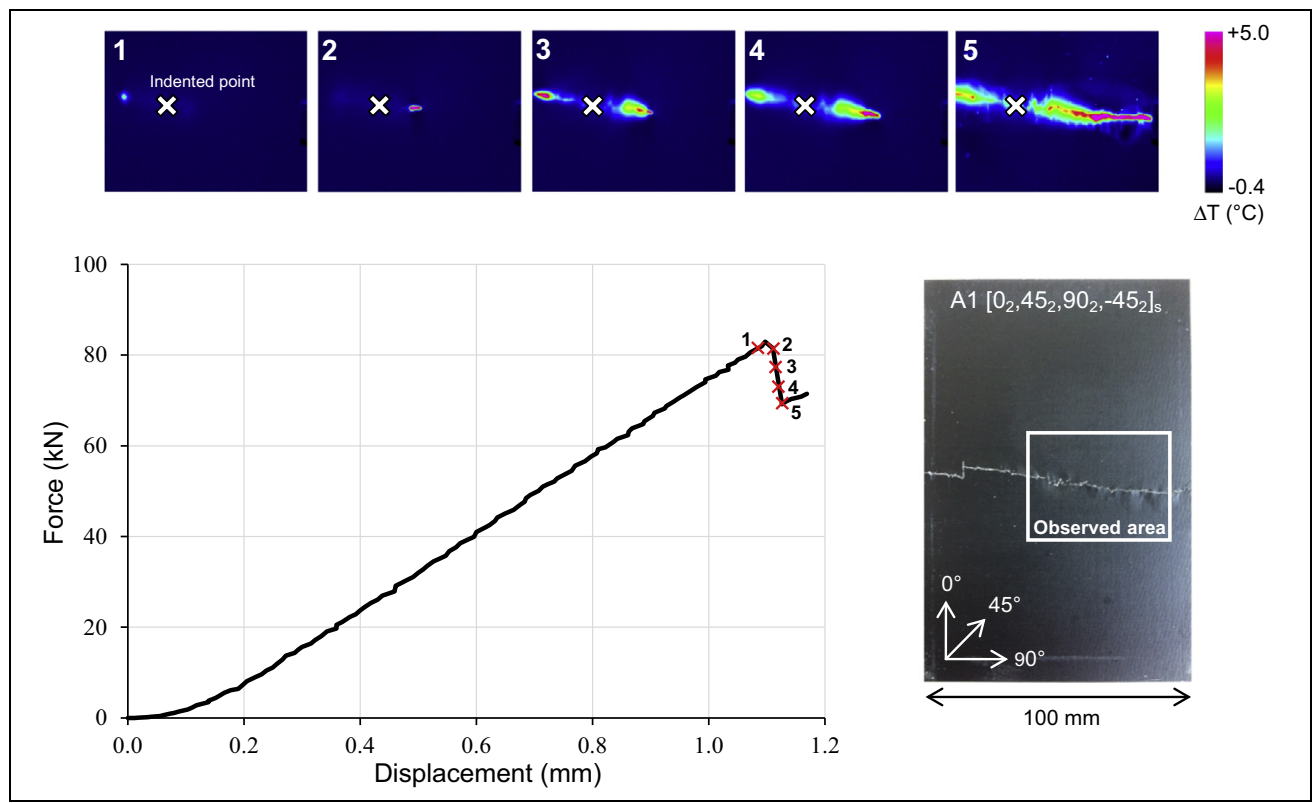

(b)

Fig. 4. Damage detection by infrared thermography camera associated with force-displacement curves: static indentation test (a) and CAI test (b). 


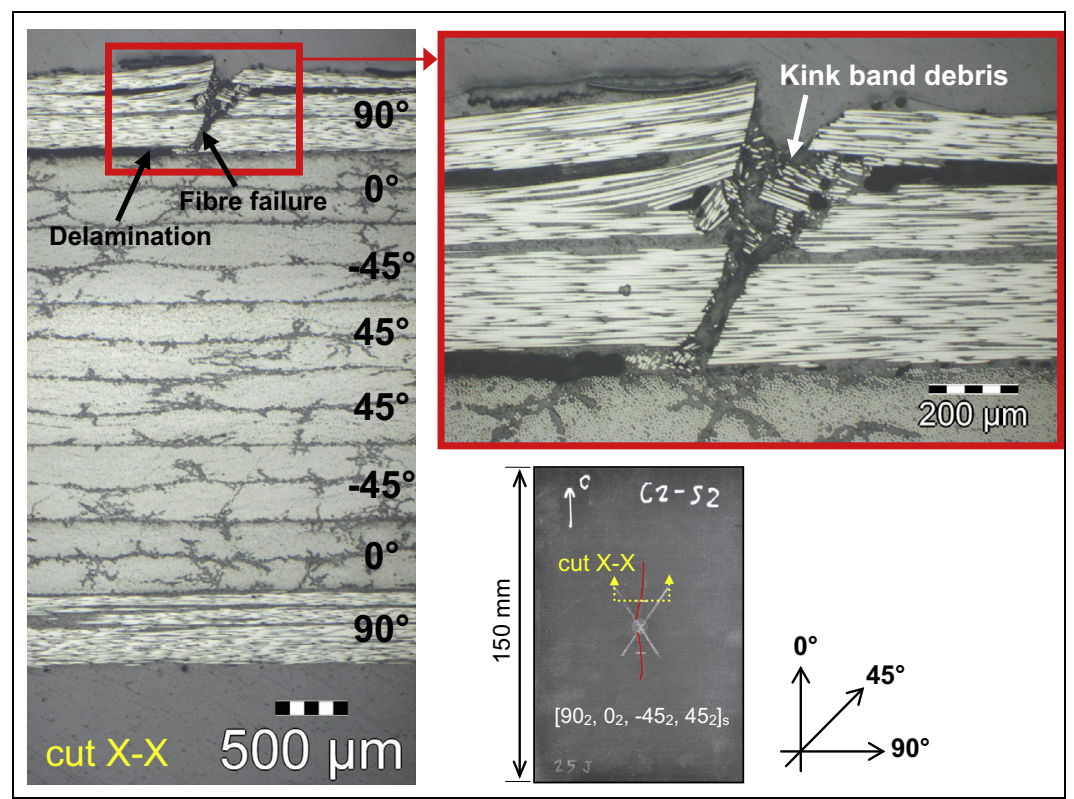

(a)

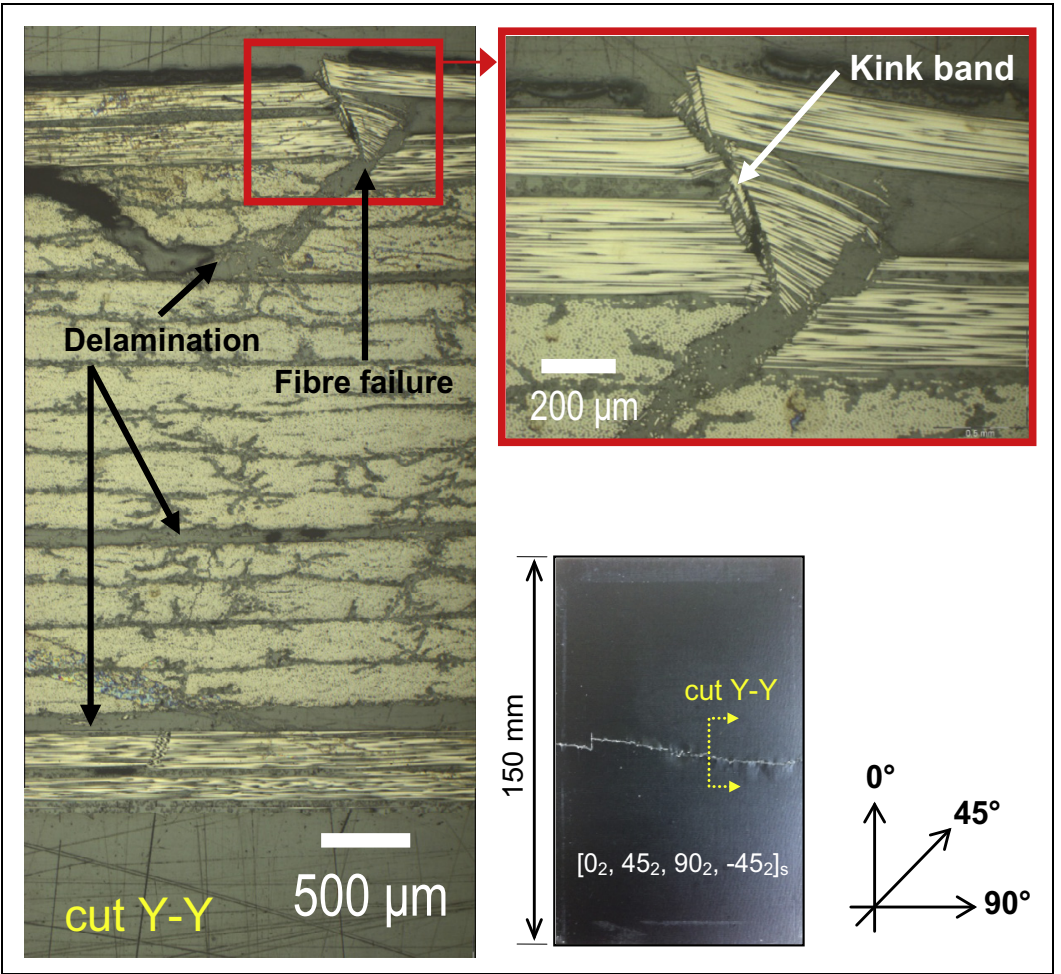

(b)

Fig. 5. Post-mortem micrographs (a) static indentation test (taken from an equivalent specimen of $25 \mathrm{~J}$-impact [25]) and (b) CAI test.

cracks of $90^{\circ}$-plies on the upper surface near indenter point are observed; meanwhile an infrared camera records the temperature on the expected zone of the crack appearance (Fig. 4a).

The specimen is subjected to out-of-plane load until approximately $5 \mathrm{~mm}$ (for a total energy of $25 \mathrm{~J}$ ). As can be seen on the force-displacement curve in Fig. 4a, during loading the response is not linear due to internal damage. Matrix cracking and delamination commonly occur prior to fiber failure [25]. The damage near the surface can be detected by an infrared thermography camera, in particular the double-ply fiber compressive failure, as the post-mortem micrograph shows in Fig. 5a. This fiber compressive failure arises from $3.5 \mathrm{~mm}$-displacement and gradually continues to propagate until the end of loading state.

The second test application is CAI (Fig. 3b) [26]. Failure of the outermost $0^{\circ}$-plies of $\left[00_{2}, 45_{2}, 90_{2},-45_{2}\right]_{s}$ laminates, directly subjected to compressive loading, is investigated. Then, the critical energy release rate is measured based on an evaluation of the heat dissipation around the observed compressive cracks. Prior to the CAI test, the plate composite laminate has been damaged by static loading in the center of the specimen at $27.3 \mathrm{~J}$-total energy [26]. Consequently, this specimen is placed inside CAI fixture and is subjected to in-plane compressive load at a displacement rate of 
$0.6 \mathrm{~mm} / \mathrm{min}$. LVDT sensors measure the imposed displacement and the plate deflection. Thanks to the configuration of $0^{\circ}$-plies on the exterior, compressive failure can be easily observed. Since the CAI final failure is generally induced from the indented point, an infrared camera captures the temperature variation on the zone near this point (Fig. 4b).

During the CAI test, the force vs. displacement plot is relatively linear until the collapse of the specimen or final failure. The infrared thermography camera detects that the damage initiation occurs just before the final failure. It is not clear that the damage shown at points $1-5$ in Fig. $4 \mathrm{~b}$ is caused by the collapse of the plate due to bending or due to the only propagation of fiber cracks. However, this damage is proved to be a compressive fiber failure, as shown by the kink bands in Fig. 5b. Thus, we assumed that the heat detected by the infrared camera is caused by this fiber compressive failure. Note that Fig. $5 b$ shows the micrograph of fiber failure mixed to other failure modes i.e. matrix cracking and delamination but it was taken after the final failure occurred.

\section{Compressive fiber failure toughness using IRT}

The concept of determining the critical energy release rate by using infrared thermography technique is based on thermo-mechanical background. The full details can be found in [24]. The principle of IRT is to use heat diffusion equation to evaluate the intrinsic dissipation of the damaged material. Indeed IRT makes possible to evaluate the left term of heat diffusion equation using spatial and temporal data of the film and thus the right term with the intrinsic dissipation:

$\rho C \frac{d \theta}{d t}-\left[k_{x x} \frac{\partial^{2} \theta}{\partial x^{2}}+k_{y y} \frac{\partial^{2} \theta}{\partial y^{2}}+k_{z z} \frac{\partial^{2} \theta}{\partial z^{2}}\right]=\phi_{\text {int }}+s_{\text {the }}$

where $\rho$ is the mass density, $C$ the specific heat capacity, $\theta=T-T_{0}$ the temperature variation between the current state and the initial equilibrium state $T_{0}, k_{x x}\left(k_{y y}, k_{z z}\right)$ the conductivity in $x(y, z)$ direction, $\phi_{\text {int }}$ the intrinsic dissipation and $s_{\text {the }}$ the thermo-mechanical coupling. In the right term of the heat diffusion equation, we assume that the thermo-mechanical coupling is neglected compared to intrinsic dissipation $\left(s_{\text {the }} \ll \phi_{\text {int }}\right)[17,20,24]$. Moreover the irreversible dissipation $\phi_{\text {irrev }}$, which is necessary to evaluate the fracture toughness, can be separated into two parts, the intrinsic dissipation $\phi_{\text {int }}$ evaluated using IRT and the stored energy $\phi_{\text {stored }}$ :

$\phi_{\text {irrev }}=\phi_{\text {int }}+\phi_{\text {stored }}$

Practically the stored energy is very difficult to evaluate and the Taylor-Quinney coefficient [21] is needed. This coefficient denotes the ratio of energy dissipated as heat, the intrinsic dissipation, to irreversible energy:

$\beta=\frac{\int_{t_{A}}^{t_{A+d A}} \int_{\Omega_{\text {fis }}} \phi_{\text {int }} \cdot d V \cdot d t}{\int_{t_{A}}^{t_{A+d A}} \int_{\Omega_{\text {fis }}} \phi_{\text {irrev }} \cdot d V \cdot d t} \approx \frac{d W_{\text {diss }}}{d W_{\text {irrev }}}$

More precisely, the Taylor-Quinney coefficient is defined as the ratio of the integrals over time and space of the intrinsic dissipation $d W_{\text {diss }}$ and of the irreversible energy $d W_{\text {irrev }}$, where $t_{A}\left(t_{A+d A}\right)$ denotes the time during which the crack area is $A(A+d A)$ and $\Omega_{\text {fis }}$ a volume containing the crack (Fig. 6) [20]. The TaylorQuinney coefficient is included between 0 and 1 , and is equal to 1 if all the dissipated energy is converted into heat. Then if this coefficient is known, it is possible to evaluate the fracture toughness $G_{I c}$ using the dissipated energy evaluated with IRT:

$G_{I c}=\frac{d W_{\text {irrev }}}{d A}=\frac{d W_{\text {diss }}}{\beta \cdot d A}$

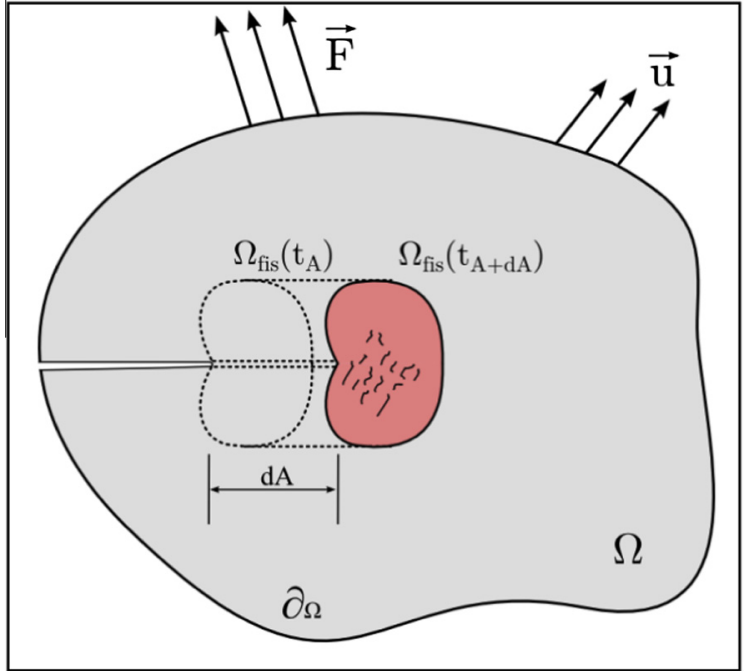

Fig. 6. Diagram of the crack progress and of the integration volume [20].

Then the IRT allows a localized measure of the fracture toughness but it is necessary to know $\beta$ which depends on damage mechanisms. In the literature, this parameter may vary from $50 \%$ and $100 \%[17,21,24]$, thus an accurate estimation of energy release rates associated with crack propagation is probably uncertain and this is a debated issue for determining the value of $G_{I c}$ by this approach.

In this work, since the tested laminate has different plies orientation, fiber failure may damage certain plies but not throughout the thickness of the laminate. Since the temperature field is not constant through the thickness of the laminate, the 2D heat diffusion problem is not reliable to solve it $[15,16]$. Thus, only the heat source of the compressive fiber failure cracks on the surface is considered. A 3D thermal analysis is used and the heat source, assumed to be uniform through the damage plies, can be written as (Fig. 7a):

$$
\begin{aligned}
\omega_{h s}= & \omega_{\max } \cdot\left[H\left(z-z_{0}\right)-H\left(z-z_{1}\right)\right] \cdot e^{-\left(\frac{\left(x-x_{0}\right)^{2}}{2 \sigma_{x}^{2}}+\frac{\left(y-y_{0}\right)^{2}}{2 \sigma_{y}^{2}}\right)} \\
& \cdot e^{-\left(\frac{\left(t-t_{0}\right)^{2}}{2 \sigma_{t}^{2}}\right)}
\end{aligned}
$$

where $\omega_{h s}$ represents the total volume heat source $\left(\omega_{\text {hs }}=\phi_{\text {int }}+s_{\text {the }}+r_{\text {ext }} \approx \phi_{\text {int }}\right), \omega_{\max }$ the maximum value of heat source, $x_{0}$ and $y_{0}$ the space positions associated with the global coordinate $x-y$, and $t_{0}$ denotes the temporal position of the crack. $\sigma_{x}, \sigma_{y}$ and $\sigma_{t}$ are, respectively, the constants of length, width and temporal distribution which can be found in [24]. They are the optimized parameters due to ill-posed problem of temperature field evolution $[15,16,24]$. The term $\left[H\left(z-z_{0}\right)-H\left(z-z_{1}\right)\right]$ is the rectangular function corresponding to the crack thickness. Then, the temperature variation $\theta$ can be solved by $3 \mathrm{D}$ inverse heat diffusion problem:

$\rho C \frac{\partial \theta}{\partial t}-\left[k_{x x} \frac{\partial^{2} \theta}{\partial x^{2}}+k_{y y} \frac{\partial^{2} \theta}{\partial y^{2}}+k_{z z} \frac{\partial^{2} \theta}{\partial z^{2}}\right]=\omega_{h s}$

From microscopic observations (Fig. 7b), we assume that the temperature is uniform through the crack thickness (the double damaged plies near the surface) and the heat source is only due to fiber compressive failure of the double-ply whereas the heat source due to matrix cracks and delamination underneath is neglected.

For numerical calculation, the solution of thermal problem is computed by using finite difference method. A small step time 


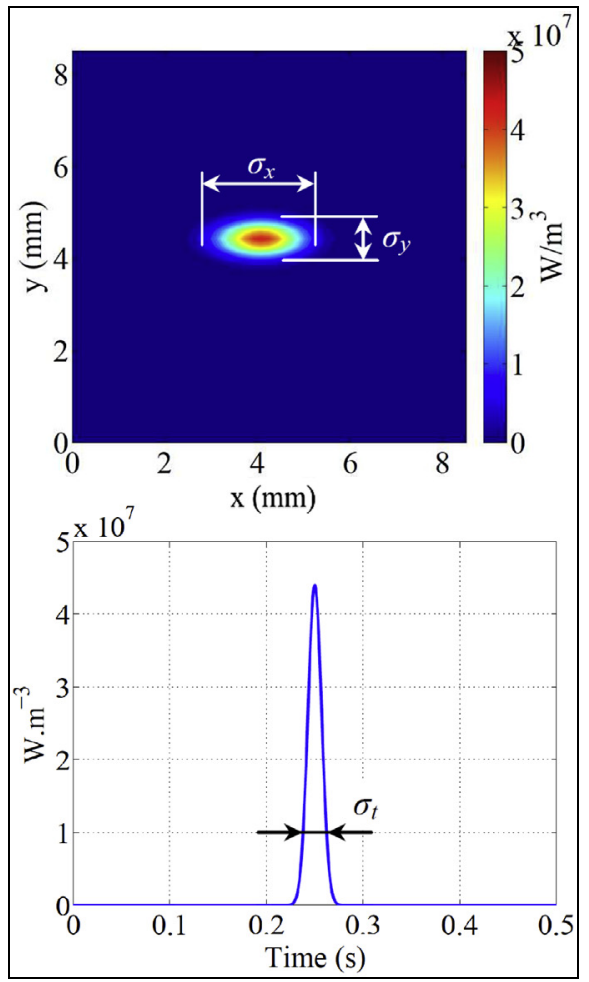

(a)

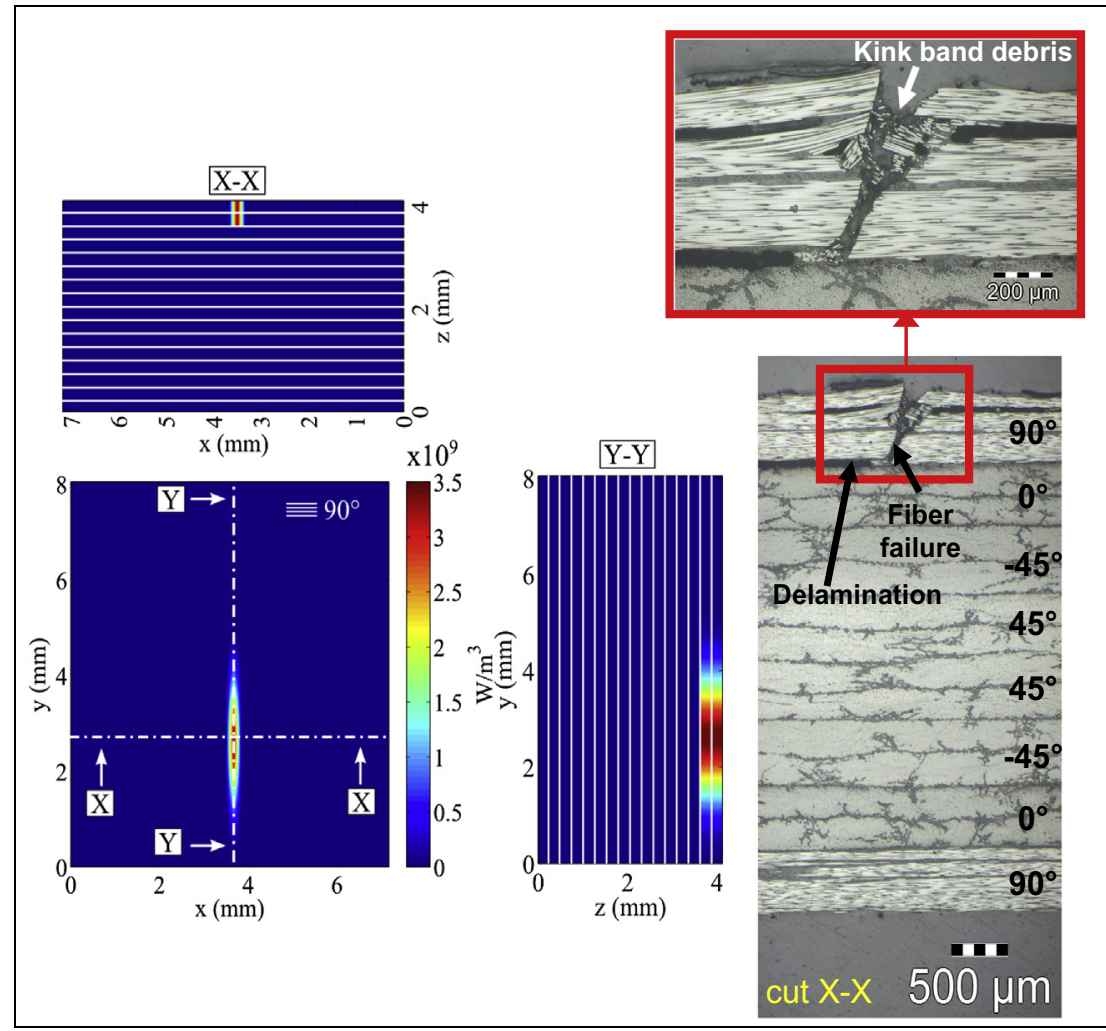

(b)

Fig. 7. Shape of the supposed total volume heat source (a) and spatial field of temperature due to compressive fiber failure of the two outer plies and comparison with the micrographic cut of the real damage (b). 


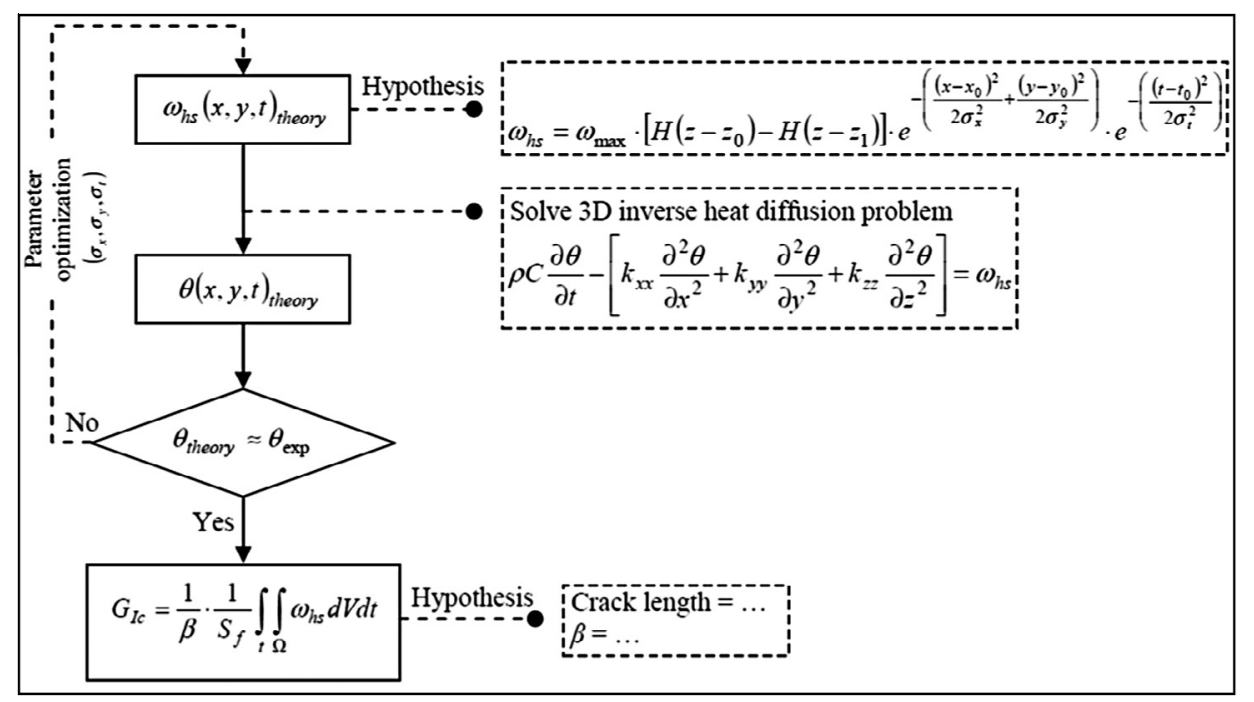

Fig. 8. Flow-chart presenting the methodology of determining the fracture toughness from thermal information obtained by IRT.

$\Delta t=5 \cdot 10^{-4} \mathrm{~s}$ is chosen in order to ensure the convergence of results and to be close to experimental conditions, the in-plane spatial discretization parameters are chosen equal to the camera resolution: $\Delta x=\Delta y=0.16 \mathrm{~mm}$. The theoretical heat sources are determined on three different zones of each test, as shown in Fig. 9a for the static indentation test and Fig. 10a for CAI test. According to the proposed methodology [24], the optimization parameters $\left(\sigma_{x}, \sigma_{y}, \sigma_{t}\right)$ are identified by trial-and-error method in order to correlate with the experimental temperature variation $\theta_{\text {exp }}$, both in space and time (Fig. 8).

An example of experimental-numerical correlation of static indentation test (zone 3) is presented in Fig. 9. Zone 3 is presented but similar results are obtained for zones 1 and 2. Fig. 9d shows the evolution of average temperature cooling as a function of time. At temperature peak, a comparison of the temperature variation field of the crack between the experiment and the theoretical calculation is shown respectively in Fig. 9b and c. The evolution of temperature along $X-X$ and $Y-Y$ axes are presented respectively in Fig. 9e and f. As can be seen, Fig. 9b and show a good correlation between experimental results and theoretical calculation after the selection of optimized parameters.

Another example of CAI test (zone 3), after the process of parameter optimization, is also presented: Fig. $10 \mathrm{~b}$ and $\mathrm{f}$ shows a good agreement between experimental and theoretical results even if an uncorrelated experimental cooling is found in Fig. 10d. Indeed, the instability of the evolution of experimental temperature is clearly caused by a combination of other failure modes (delamination and matrix cracking) occurring during the crack propagation (Fig. 10b); thus precise numerical cooling cannot be obtained. Thanks to a good agreement on other factors i.e. evolution of temperature along $X-X$ and $Y-Y$ axes, we still rely on the chosen optimized parameters (Table 2). The above results confirm that the heat sources due to plies compressive failure are well assumed by the theoretical approach for both static indentation test and CAI test, and the use of the proposed thermography methodology is applicable for UD plies. We performed it on six studied zones from two different test applications. Table 2 presents the selected optimization parameters for all cases. Of course due to the experiments orientation, the crack propagation is in the $y$-direction for the indentation test (Fig. 9) and in the $x$-direction for the CAI test (Fig. 10). Then $\sigma_{x}\left(\sigma_{y}\right)$ denotes the crack width for the indentation (CAI) test. This value is particularly interesting to consider because it denotes the zone where the energy is dissipated due to the damage crack. In fact this zone may be the size of the kink band plus the size of the damaged zone following this kink band. This damaged zone can be due to matrix pseudoplasticity, matrix cracks or matrix/fiber debonding. Particular values of $\sigma_{y}$ and $\sigma_{x}$ for CAI test in zone 1 should be noticed. Here the crack is caused by the specimen's collapse at final failure which does not gradually propagate like in other zones but instantaneously (one camera picture). Consequently, the parameter optimization process leads to a unique heat source with a $16.5 \mathrm{~mm}$ length equal to the width of the zone crossed by the crack. The high value for the source width $\left(\sigma_{y}=0.248 \mathrm{~mm}\right)$ can be induced both by the use of this unique long source and by the presence of other failure modes as mentioned above. But except for this case, the value of the crack width is relatively constant and is approximatively equal to $0.06 \pm 0.02 \mathrm{~mm}$. It is difficult to compare this value with the micrographs of the kink bands (Fig. 5) because they should be degraded by the crack growth, the crushing and the final failure. But this value is coherent with the observations reported in $[11,12]$ where kink band crack width is in a range of $50-100 \mu \mathrm{m}$.

Afterward, an estimation of the critical energy release rate $G_{I c}^{\text {comp }}$ can be computed following Eq. (4) and (5):

$G_{I c}=\frac{\Delta W_{\text {diss }}}{\beta \cdot \Delta A}=\frac{\int_{0}^{t_{A}} \int_{\Omega_{f i s}} \phi_{i n t} \cdot d V \cdot d t}{\beta \cdot \Delta A}=\frac{\int_{0}^{t_{A}} \int_{\Omega_{f i s}} \omega_{h s} \cdot d V \cdot d t}{\beta \cdot \Delta A}$

where $\Delta A$ denotes the crack surface determined using thermography data. Indeed the heating of the crack tip permits to follow the crack growth during the test. Finally, the heat source $\omega_{h s}$ is obtained thanks to the maximum value of heat source $\omega_{\max }$ from the experiment and the optimization parameters previously defined.

\section{Results}

As mentioned before, a sensitive issue is still the ratio of the energy dissipated as heat to the irreversible mechanical energy $(\beta)$. For metallic materials, some studies exist in the literature. For example, Kapoor and Nemat-Nasser [22] show $\beta$ is close to 1 for a Ta-2.5\% W. Bhalla et al. [31] measured values of $\beta$ between 0.5 and 1 depending on the strain (Fig. 11a) for an annealed 302 stainless steel. With the same material, Zehnder at al. [32] studied crack in a $0.8 \mathrm{~mm}$ plate for stable tearing growth. They show that 
quantitative imaging of the crack tip temperature field using IRT can be used to resolve crack tip energy flux and to measure the energy release rate (Fig. 11b).

However, for the carbon/epoxy material used in this study no values are available in the literature. In addition, the value of this ratio is both strain and strain-rate sensitive [23,24,30]. Li and Lambros [23] measured, for a PC material, ratio of dissipative work converted into heat between $100 \%$ for low strain and 50\% for high strain.

With regard to values of $\beta$ in the literature for polymer materials, two cases were studied. In the first case, half of the mechanical energy is dissipated as heat: $\beta=0.5$ and in the second case, the thermal dissipated energy represents $90 \%$ of the total work: $\beta=0.9$. In the future, additional works will be necessary to compare the measure of fracture toughness using IRT with standard methods (DCB, ENF, etc.) in order to evaluate the $\beta$ coefficient and to test the reliability of this method. Nevertheless it is difficult in the present case of compressive fiber failure to compare the IRT with standard techniques, because no standard test is available for this failure.
Finally, the critical energy release rate fiber $G_{I c}^{\text {comp }}$ can be computed with the two $\beta$ values of 0.5 and 0.9 (Table 1 ). The obtained average values for static indentation test are $\mathbf{3 2 . 6} \mathrm{N} / \mathrm{mm}$ and $58.7 \mathrm{~N} / \mathrm{mm}$ for $\beta=0.9$ and 0.5 , respectively. And the obtained average values for CAI test are $42.5 \mathrm{~N} / \mathrm{mm}$ and $76.6 \mathrm{~N} / \mathrm{mm}$ for $\beta=0.9$ and 0.5 , respectively. In fact, the true fracture toughness value should be closer to the higher value, because $\beta$ should be closer to 0.9 than to 0.5 . Indeed the phenomenon of compressive fiber failure is rather a brittle phenomenon with a lot of matrix cracks, fiber/resin debonding and fiber failures.

These results show the fracture toughness of compressive fiber failure for static indentation test is lower than CAI. The stability of the crack growth for the static indentation, contrary to the unstable crack growth for the CAI, could explain this result. Indeed a crack growth could induce less secondary damage, such as delamination or matrix cracking, and thus induces less dissipated energy. Of course this explanation should be confirmed and considered with caution. Another explanation could be the variation of the $\beta$ coefficient. Indeed its value could be different depending on stable or unstable crack growth and thus it is

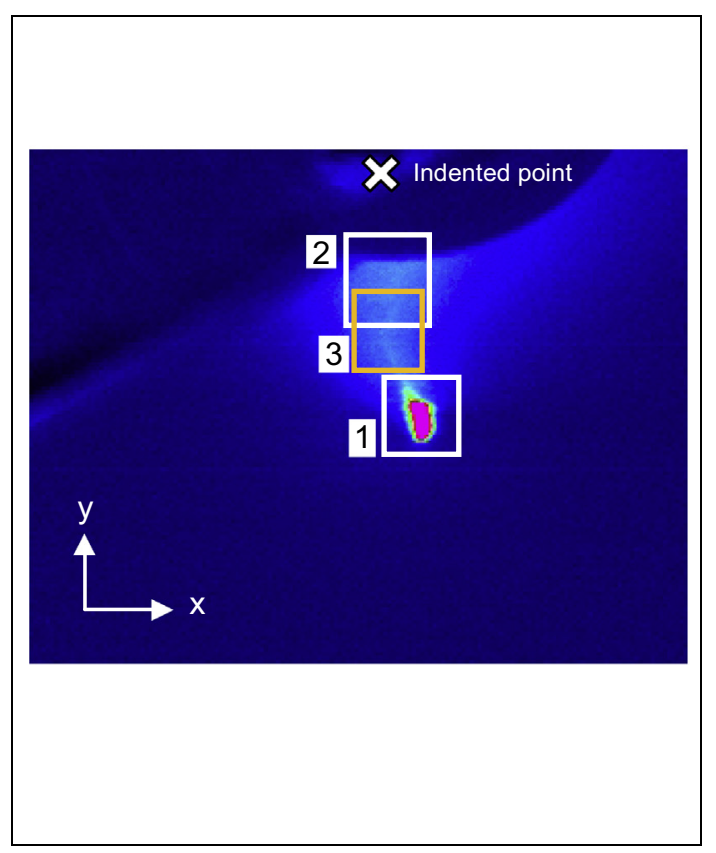

(a)

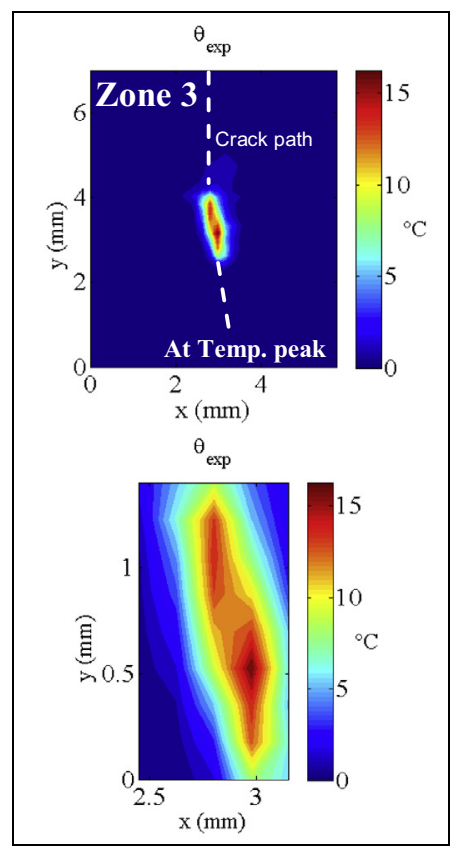

(b)

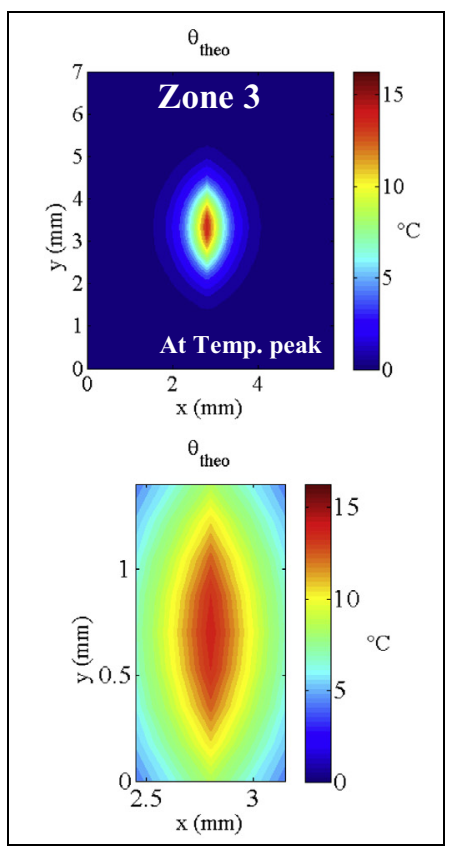

(c)

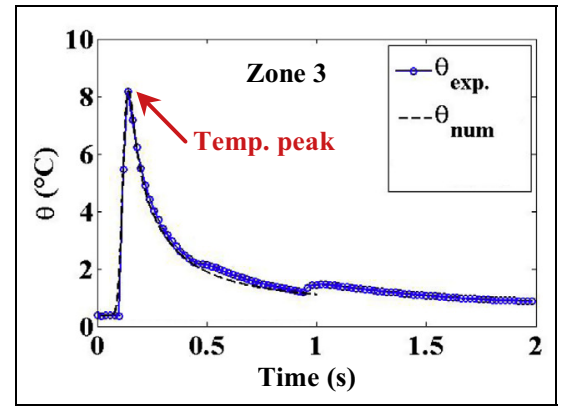

(d)

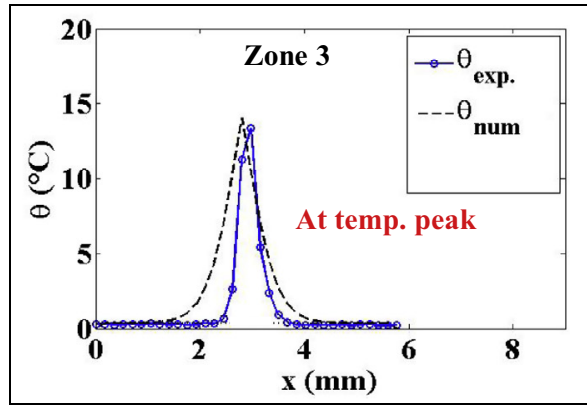

(e)

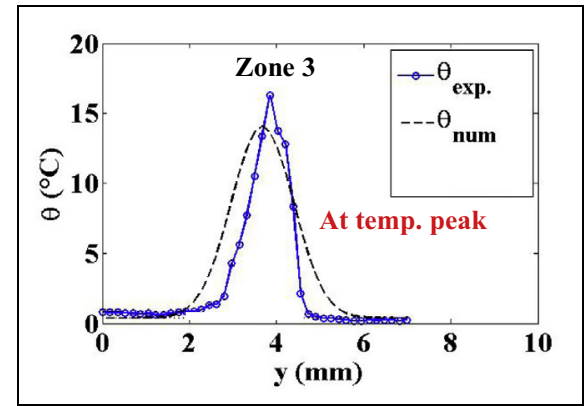

(f)

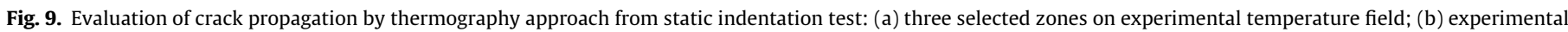

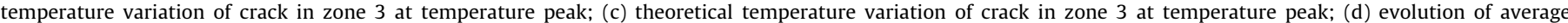

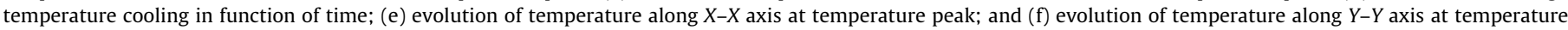
peak. 


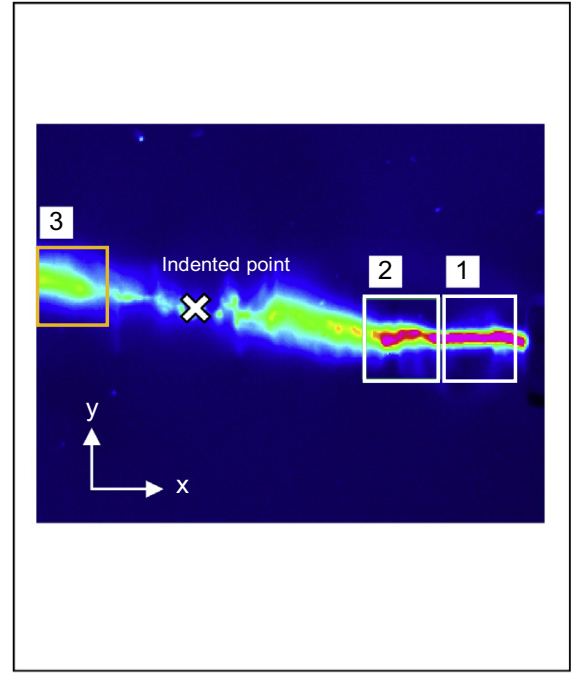

(a)

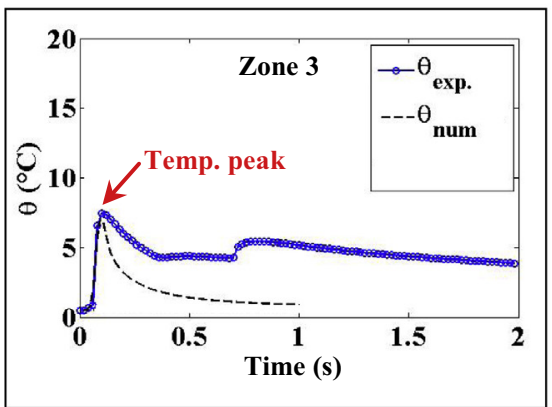

(d)

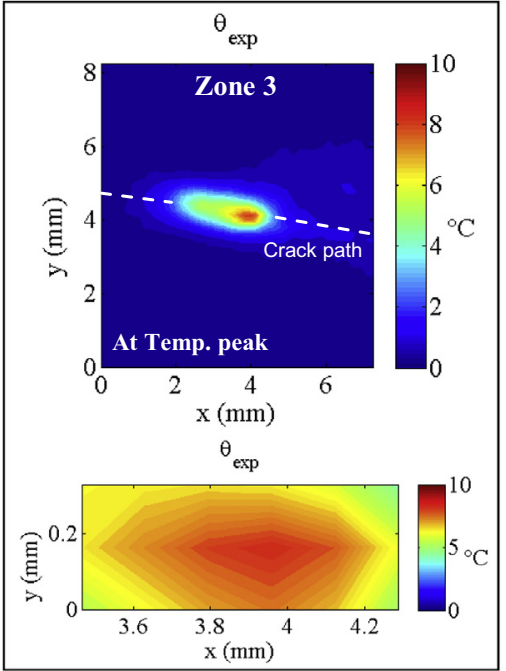

(b)

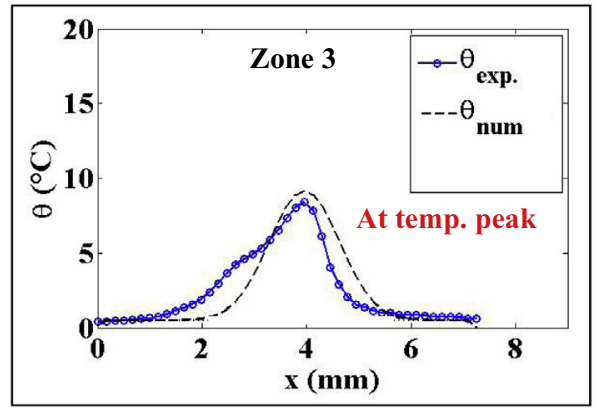

(e)

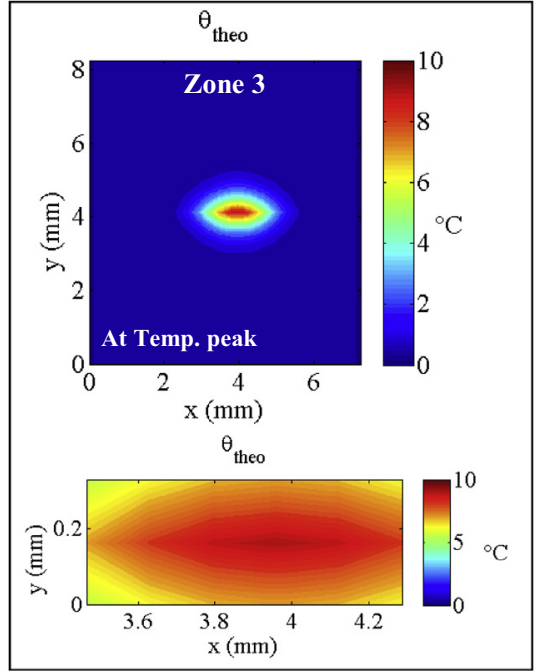

(c)

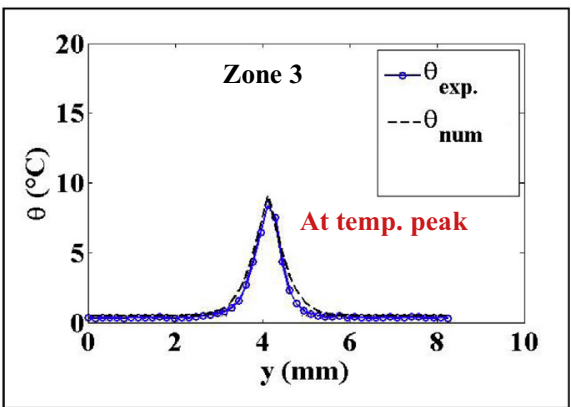

(f)

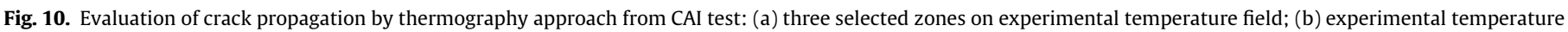

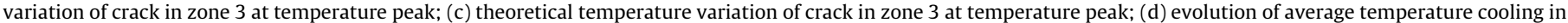
function of time; (e) evolution of temperature along $X-X$ axis at temperature peak; and (f) evolution of temperature along $Y-Y$ axis at temperature peak.

Table 2

Values of theoretical heat source parameters obtained for the three zones of each test, and calculated values of toughness.

\begin{tabular}{|c|c|c|c|c|c|c|c|}
\hline \multirow[t]{2}{*}{ Test } & \multirow[t]{2}{*}{ Zone no. } & \multicolumn{3}{|c|}{ Optimization parameters } & \multirow[t]{2}{*}{$\omega_{\max }\left(\mathrm{W} \mathrm{m}^{-3}\right)$} & \multirow[t]{2}{*}{$\Delta A\left(\mathrm{~mm}^{2}\right)$} & \multirow[t]{2}{*}{$G_{I c}^{\text {fiber }, C}(\mathrm{~N} / \mathrm{mm})$} \\
\hline & & $\sigma_{x}(\mathrm{~mm})$ & $\sigma_{y}(\mathrm{~mm})$ & $\sigma_{t}(\mathrm{~s})$ & & & \\
\hline \multirow[t]{3}{*}{ Static Indentation } & 1 & 0.083 & 0.990 & $12 \mathrm{e}-3$ & 2.80 e 9 & 0.963 & $40-71$ \\
\hline & 2 & 0.041 & 0.825 & $10 \mathrm{e}-3$ & 3.50 e9 & 0.525 & $32-57$ \\
\hline & 3 & 0.041 & 0.660 & $12 \mathrm{e}-3$ & 2.55 e9 & 0.438 & $27-48$ \\
\hline \multirow[t]{3}{*}{ CAI } & 1 & 16.50 & 0.248 & $12 \mathrm{e}-3$ & 1.40 e9 & 3.220 & 41-73 \\
\hline & 2 & 0.866 & 0.083 & $12 \mathrm{e}-3$ & 2.05 e9 & 0.495 & 44-79 \\
\hline & 3 & 0.660 & 0.041 & $12 \mathrm{e}-3$ & 1.75 e9 & 0.165 & $43-77$ \\
\hline
\end{tabular}

difficult to conclude if the higher value for CAI test is true or only due to the IRT.

In spite of the difficulties to estimate the $\beta$ coefficient, this measured fracture toughness of compressive fiber failure is also relatively consistent with those found in a previous work with the same material (T700GC/M21 carbon/epoxy) [25] of $40 \mathrm{~N} / \mathrm{mm}$ using a FE analysis of impact damage. This value is also relatively consistent with the literature with similar materials. For example, Pinho et al. [6] evaluated the fiber $G_{I c}^{\text {comp }}$ of T300/913 carbon-epoxy laminates to $79.9 \mathrm{~N} / \mathrm{mm}$ and Soutis and Curtis [7] the fiber $G_{I c}^{\text {comp }}$ of T800/924C carbon-epoxy laminates to $34-39 \mathrm{~N} / \mathrm{mm}$. Of course, it is difficult to compare these values of fracture toughness together because the carbon fibers and the epoxy resin are different. Unfortunately it is difficult to find fracture toughness of compressive fiber failure in the literature for carbon/epoxy material and, as far as we know, there is no existing value for T700GC/M21.

\section{Conclusion}

IRT is a very interesting technique to evaluate the fracture toughness in composite materials easily and locally. The main advantages of this technique are:

- IRT is a local technique which makes possible the evaluation of the dissipated energy not taking the secondary damage types into account, such as secondary cracks in the sample or crushing under the boundary conditions. 


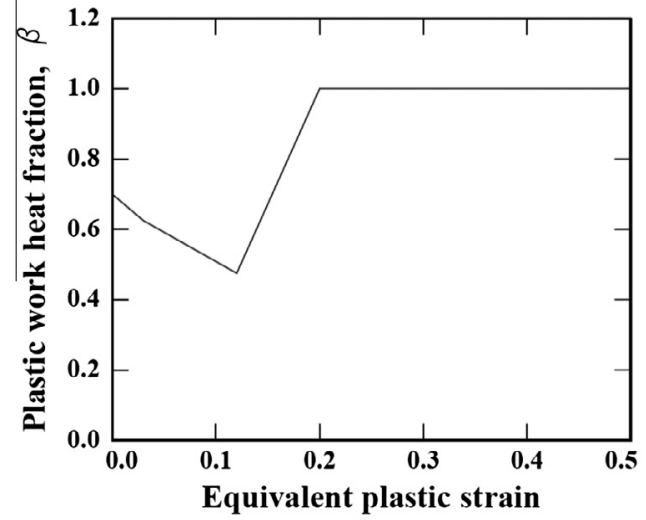

(a)

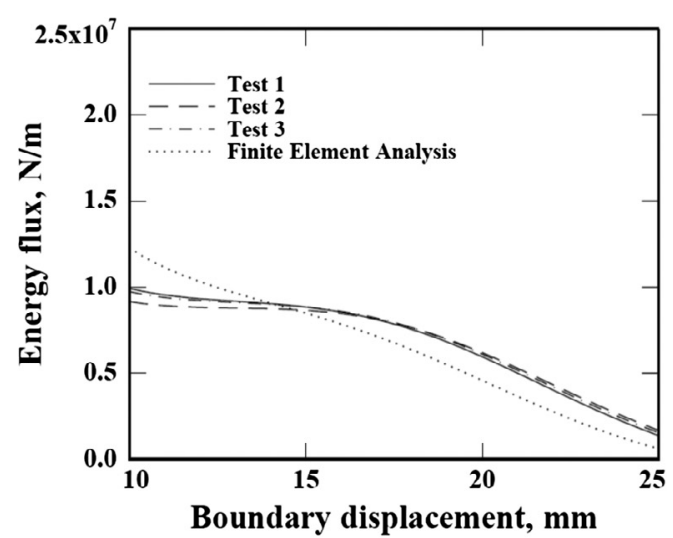

(b)

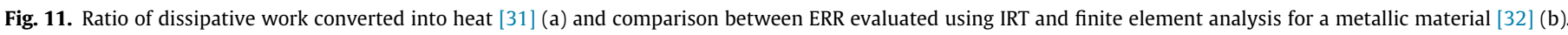

- The fracture toughness can be computed even for experiments where the stiffness variation remains small and for which the standard techniques, such as area or compliance methods, are not relevant.

- IRT allows to obtain energy and space information at the same time. The energy information makes possible to evaluate the energy dissipated by the crack. The space information makes possible not only to evaluate the crack length but also as a function of time and space to evaluate the localization and the type of damage, in particular the size of the damaged zone following the main crack.

But the main drawback of the IRT is the knowledge of the Taylor-Quinney coefficient. Indeed this coefficient which denotes the ratio of energy dissipated as heat, the intrinsic dissipation, to irreversible energy, depends on the damage type. Thus an accurate estimation of energy release rates associated with crack propagation is probably uncertain and this is a debated issue for determining the value of fracture toughness by this approach.

In this study, damage of compressive fiber failure in unidirectional composite laminate has been chosen for its difficulty to evaluate toughness. The infrared thermography has been used to follow compressive failure mode developing during an indentation test and a compression after impact test, and to evaluate the fracture toughness of compressive fiber failure. The average values of $G_{I c}^{\text {comp }}$, for static indentation test and CAI test are respectively $32.6 \mathrm{~N} / \mathrm{mm}$ and $42.5 \mathrm{~N} / \mathrm{mm}$. These obtained results are a good match with the value found in a previous work [25] $(40 \mathrm{~N} / \mathrm{mm})$ based on a FE analysis of impact damage and are coherent with the literature $[6,7]$.

\section{References}

[1] Falzon BG, Apruzzese P. Numerical analysis of intralaminar failure mechanisms in composite structures. Part I: FE implementation. Compos Struct 2011;93(2):1039-46.

[2] Donadon MV, Iannucci L, Falzon BG, Hodgkinson JM, de Almeida SFM. A progressive failure model for composite laminates subjected to low velocity impact damage. Compos Struct 2008;86:1232-52.

[3] Lopes CS, Camanho PP, Gürdal Z, Maimí P, González EV. Low-velocity impact damage on dispersed stacking sequence laminates Part II: Numerical simulations. Compos Sci Technol 2009;69(7-8):937-47.

[4] Israr HA, Rivallant S, Bouvet C, Barrau JJ. Finite element simulation of $0^{\circ} / 90^{\circ}$ CFRP laminated plates subjected to crushing using a free-face-crushing concept. Composites: Part A 2014;62:16-25.

[5] Achard V, Bouvet C, Castanié B, Chirol C. Discrete ply modelling of open hole tensile tests. Compos Struct 2014;113:369-81.
[6] Pinho ST, Robinson P, Iannucci L. Fracture toughness of the tensile and compressive fibre failure modes in laminated composites. Compos Sci Technol 2006;66:2069-79.

[7] Soutis C, Curtis PT. A method for predicting the fracture toughness of CFRP laminates failing by fibre microbuckling. Compos Part A: Appl Sci Manuf 2000;31:733-40.

[8] Mathews MJ, Swanson SR. Characterization of the interlaminar fracture toughness of a laminated carbon/epoxy composite. Compos Sci Technol 2007:67:1489-98.

[9] Davies P, Blackman BRK, Brunner AJ. Standard test methods for delamination resistance of composite materials: current status. Appl Comp Mater 1998:5:345-64.

[10] Prombut P. Caractérisation de la propagation de délaminage des stratifiés composites multidirectionnels. PhD. thesis, Université de Toulouse; 2007.

[11] Jumahat A, Soutis C, Jones F, Hodzic A. Fracture mechanisms and failure analysis of carbon fibre/toughened epoxy composites subjected to compressive loading. Compos Struct 2010;92(2):295-305.

[12] Gutkin R, Pinho S, Robinson P, Curtis P. On the transition from shear-driven fibre compressive failure to fibre kinking in notched CFRP laminates under longitudinal compression. Compos Sci Technol 2010;70(8):1223-31.

[13] Chrysochoos A, Louche H. An infrared image processing to analyse the calorific effects accompanying strain localisation. Int J Eng Sci 2000;38:1759-88.

[14] Dumoulin S, Louche H, Hopperstad O, Borvik T. Heat sources, energy storage and dissipation in high-strength steels: experiments and modeling. Eur J Mech A/Solids 2010;29:461-74.

[15] Wattrisse B, Muracciole JM, Chrysochoos A. Thermomechanical effects accompanying the localized necking of semi-crystalline polymers. Int J Therm Sci 2002;41(5):422-7.

[16] Chrysochoos A, Chezeaux JC, Caumon H. Analyse thermomécanique des lois de comportement par thermographie infrarouge. Rev Phys Appl $1989 ; 24(2): 215-25$.

[17] Naderi M, Kahirdeh A, Khonsari M. Dissipated thermal energy and damage evolution of glass/epoxy using infrared thermography and acoustic emission. Compos Part B: Eng 2012;43(3):1613-20.

[18] Rice J. A path independent integral and the approximate analysis of strain concentration by notches and cracks. J Appl Mech 1968;35:379-86.

[19] Freund L, Hutchinson J. High strain-rate crack growth in rate-dependent plastic solids. J Mech Phys Solids 1985;33(2):169-91.

[20] Soumahoro Z. Etude du couplage thermomécanique dans la propagation dynamique de fissure. Ph.D. thesis, Ecole Polytechnique; 2005.

[21] Taylor GI, Quinney $H$. The latent energy remaining in a metal after cold working. Proc R Soc Lond, A 1934;143(849):307-26.

[22] Kapoor R, Nemat-Nasser S. Determination of temperature rise during high strain rate deformation. Mech Mater 1998;27(1):1-12.

[23] Li Z, Lambros J. Strain rate effects on the thermomechanical behavior of polymers. Int J Solids Struct 2001;38(20):3549-62.

[24] Lisle T, Bouvet C. Pastor ML, Margueres P. Prieto Corral R. Damage analysis and fracture toughness evaluation in a thin woven composite laminate under static tension using infrared thermography. Compos Part A 2013;53:75-87.

[25] Hongkarnjanakul N, Bouvet C, Rivallant S. Validation of low velocity impact modelling on different stacking sequences of CFRP laminates and influence of fibre failure. Compos Struct 2013;106:549-59.

[26] Rivallant S, Bouvet C, Abi Abdallah E, Broll B, Barrau JJ. Experimental analysis of CFRP laminates subjected to compression after impact: the role of impactinduced cracks in failure. Compos Struct 2014;111:147-57.

[27] Tian T, Cole KD. Anisotropic thermal conductivity measurement of carbonfiber/epoxy composite materials. Int J Heat Mass Transf 2012;55(2324):6530-7. 
[28] Sweeting R, Liu X. Measurement of thermal conductivity for fibre-reinforced composites. Compos Part A: Appl Sci Manuf 2004;35(7-8):933-8.

[29] Fosbury A, Wang S, Pin YF, Chung DDL. The interlaminar interface of a carbon fiber polymer matrix composite as a resistance heating element. Compos Part A: Appl Sci Manuf 2003;34(10):933-40.

[30] Rittel D. On the conversion of plastic work to heat during high strain rate deformation of glassy polymers. Mech Mater 1999;31(2):131-9.
[31] Bhalla K, Zehnder A, Han X. Thermomechanics of slow stable crack growth: closing the loop between experiments and computational modeling. Eng Fract Mech 2003;70(17):2439-58.

[32] Zehnder A, Babinsky E, Palmer T. Hybrid method for determining the fraction of plastic work converted to heat. Exp Mech 1998;38(4):295-302. 